同期無依存型光カオス秘匿通信のノイズ印加によるビットエラー制御

\author{
海老澤 賢史 \\ 東京理科大学 理工学部 電気電子情報工学科（广278-8510 千葉県野田市山崎2641）
}

\title{
Bit Error Control by Applying Noise in Synchronization-Independent Optical-Chaotic Communication
}

\author{
Satoshi EBISAWA \\ Department of Electrical Engineering, Faculty of Science and Technology, \\ Tokyo University of Science, 2641 Yamazaki, Noda, Chiba 278-8510
}

(Received February 2, 2011)

\begin{abstract}
Chaotic secure communication in a chaotic laser diode transmitter-receiver array scheme (CLDTRAS), which is dependent on hardware but independent of chaos synchronization, is investigated. The effect of an applied noise signal to a drive current of transmitter laser diode is studied, and it is shown that the bit error rate against parameter mismatches can be controlled.
\end{abstract}

Key Words: Chaotic communication, Laser chaos, Chaotic synchronization

\section{1.はじめに}

カオス発振する半導体レーザー (laser diode, LD)の応 用の一つとして, 光カオス秘匿通信が広く研究されてい る. 光カオス秘匿通信においてメッセージを符号化し復 号するには，主に広帯域なスペクトルとカオス同期現象

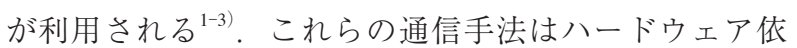
存であり, 多くは送信器のレーザーと受信器のレーザー の間のカオス同期現象 ${ }^{4}$ を利用しているため, 通信の 「鍵」にあたるものは送受信器レーザーのパラメータであ る。 また, 送信器レーザーと受信器レーザーの間のカオ ス同期現象を用いて復号するが, これらの手法では, 盗 聴者が送信器から送られてきた出力をモニターし, カオ ス同期を達成してしまえば，送信器と同期しうるLDを 利用して受信器を偽造することが可能となってしまう。 したがって, もし盗聴者が偽造した受信器を利用し, 送 信器と受信器のレーザーを同期させてしまえば，盗聴か らメッセージを守ることが難しくなってしまう．

これに対して，著者らはカオス発振レーザーの軌道不 安定性を利用した, Chaotic Laser Diode TransmitterReceiver Array Scheme (CLDTRAS) ${ }^{5,6)}$ なるデジタル秘匿 通信手法を提案している。この手法はカオス同期現象を 用いず，特定の受信器でのみ通信可能なハードウェア依 存の通信手法であるが, 送受信器のパラメー夕誤差に対 する耐性が低くビットエラーを生じ，十分にハードウェ アを特定できない，通信可能なハードウェアを特定する ために，著者らはメッセージの符号化・復号に用いる $\mathrm{LD}$ 送受信器アレイを構成するLD送受信器の数を増やし ていたが5)，メッセージを復号するためにかかる時間が
大幅に増加してしまう。これに対し，本研究ではLD送 受信器の数を増やさずにLDの駆動電流にノイズを印加 することで，通信可能なハードウェアを特定する方法に ついて数值シミュレーションを用い議論する。 また，そ の際のチャンネルノイズに対するビットエラーレートを 調査し，ノイズを印加しない場合とほぼ同等のチャンネ ルノイズ耐性を持つことを示す。

\section{Chaotic LD Transmitter-Receiver Array Scheme}

本研究で扱う光カオス通信手法であるCLDTRASにつ いて述べる。本手法は 2 種類のLD送受信器アレイによっ て, 異なる動的特性を持つカオス発振を生成するデジタ ル通信手法である。 Fig. 1にLD送受信器アレイの概図を 示す. LD送受信器アレイは4対の送信器LDと受信器LD から構成されている。各送信器LDには外部ミラーMに より戻り光が注入され, これらの出力はカオス発振とな る. 光アイソレーター (Optical isolator, OI)が送信器と受 信器の間に挿入され，送信器LDの出力は受信器LDに一 方向に光注入される。可変減衰器 (Variable attenuator, VA）によって戻り光や注入光の量を調節する。また，す べてのLD送受信器の対はそれぞれ独立に駆動してい る。このLD送受信器の動的特性はレート方程式を用い て記述することができる ${ }^{4,7-9)}$. 以下に1対の送受信器LD についてのレート方程式を示す.

$$
\begin{aligned}
& \frac{\mathrm{d} E_{t}(t)}{\mathrm{d} t}=\frac{1}{2} G_{t} n_{t}(t) E_{t}(t) \\
& \quad+\kappa_{t} E_{t}(t-\tau) \cos \left[\omega_{0} \tau+\phi_{t}(t)-\phi_{t}(t-\tau)\right]
\end{aligned}
$$


1 st

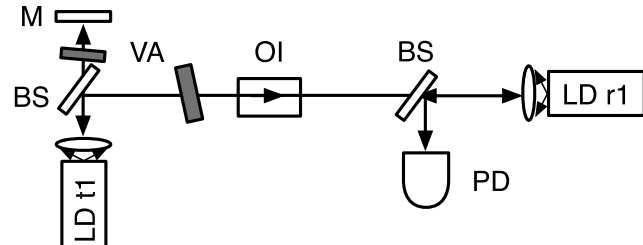

2nd

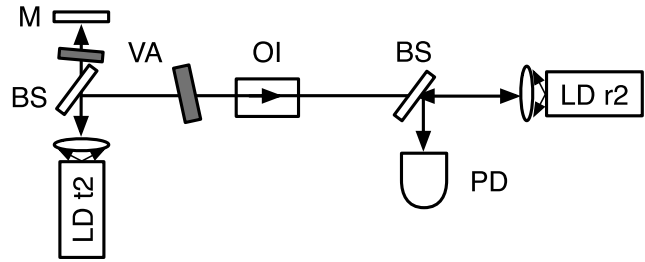

$3 r d$

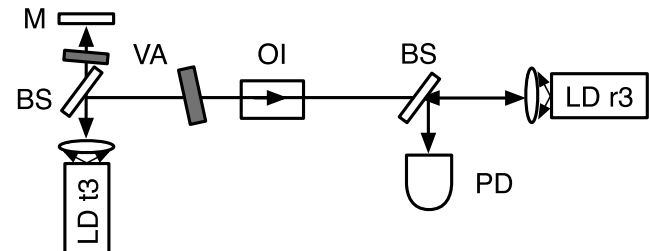

4th

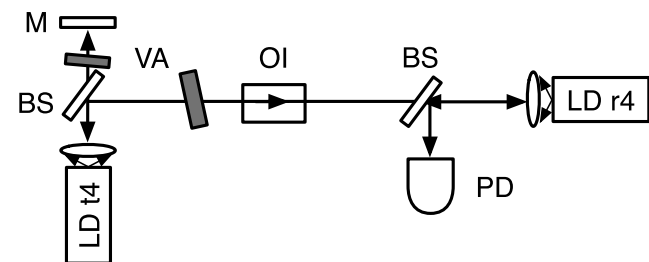

Transmitter

Receiver

Fig. 1 Scheme of chaotic laser diode transmitter-receiver array system. This consists of four pairs of a transmitter LD with optical feedback and a receiver LD with optical injection. M: mirror, VA: variable attenuator, OI: optical isolator, BS: beam splitter, PD: photodetector.

$$
\begin{gathered}
\frac{\mathrm{d} \phi_{t}(t)}{\mathrm{d} t}=\frac{1}{2} \alpha_{t} G_{t} n_{t}(t) \\
-\kappa_{t} \frac{E_{t}(t-\tau)}{E_{t}(t)} \sin \left[\omega_{0} \tau+\phi_{t}(t)-\phi_{t}(t-\tau)\right] \\
\frac{\mathrm{d} n_{t}(t)}{\mathrm{d} t}=(p-1) J_{\mathrm{th}}-\gamma_{t} n_{t}(t)-\left[\Gamma_{t}+G_{t} n(t)\right] E_{t}^{2}(t) \\
\frac{\mathrm{d} E_{r}(t)}{\mathrm{d} t}=\frac{1}{2} G_{r} n_{r}(t) E_{r}(t) \\
+\kappa_{\mathrm{inj}} E_{t}\left(t-\tau_{\mathrm{inj}}\right) \cos \left[\omega_{0} \tau_{\mathrm{inj}}+\phi_{r}(t)-\phi_{t}\left(t-\tau_{\mathrm{inj}}\right)\right] \\
\frac{\mathrm{d} \phi_{r}(t)}{\mathrm{d} t}=\frac{1}{2} \alpha_{r} G_{r} n_{r}(t) \\
-\kappa_{\mathrm{inj}} \frac{E_{t}\left(t-\tau_{\mathrm{inj}}\right)}{E_{r}(t)} \sin \left[\omega_{0} \tau_{\mathrm{inj}}+\phi_{r}(t)-\phi_{t}\left(t-\tau_{\mathrm{inj}}\right)\right] \\
\frac{\mathrm{d} n_{r}(t)}{\mathrm{d} t}=(p-1) J_{\mathrm{th}}-\gamma_{r} n_{r}(t)-\left[\Gamma_{r}+G_{r} n(t)\right] E_{r}^{2}(t)
\end{gathered}
$$

ここで, $t$ と $r$ はれぞれ送信器LDと受信器LDを示す。 $G$ は線形ゲイン係数, $\alpha$ は線幅増大係数, $\gamma\left(=1 / \tau_{s}\right)$ は キャリア減衰係数, 「はキャビティー内での光子減衰係 数である. $p J_{\mathrm{th}}$ は駆動電流を表し， $J_{\mathrm{th}}$ はLDのしきい值電
流を示す，各パラメータの值は，文献9)のものを用い る。また， $\kappa_{t}$ は送信器LDにおける戻り光の量を表す係 数, $\kappa_{\mathrm{inj}}$ は送信器LDから受信器LDへ注入される注入光の 量を表す係数であり，ここではこれらの比 $\eta=\kappa_{\mathrm{inj}} / \kappa_{t}$ を結 合係数と呼ぶ.

このようなLD送受信器アレイを2種類用いて生成した カオスの動的特性の違いによってバイナリーメッセージ を作成する。本研究では, LD送受信器の結合係数が $\eta=0.15,0.2,0.3,0.4$ のアレイ 1 と, $\eta=0.1,0.2,0.3$, 0.4のアレイ2を想定する。すなわち，送信者は「0」なる ディジットを送るときにはアレイ $1, 「 1 」$ の゙ィジットを 送るときにはアレイ2となるようにパラメータを設定す る。このとき，送信中の信号はカオス信号となり符号化 されている.

一方, 受信器LDでは送信器LDからのカオス信号が注 入されカオス信号を生成する。 $n$ 番目の受信器 $L D の ~ i$ 番 目の離散出力を $a_{n, i}$ として, 以下のべクトルで書く.

$$
\pi_{n, k}=\left(a_{n, 1}, a_{n, 2}, a_{n, 3}, \cdots \cdots a_{n, i}, \cdots \cdots a_{n, k-1}, a_{n, k}\right)
$$

本研究のシミュレーションでは, 各受信器LDの離散出 力を $10 \mathrm{ps}$ 間隔で500点サンプルする. また, ベクトル $\pi_{n, k}$ を結合して，

$$
\begin{aligned}
\prod_{N, k}= & \left(\pi_{1, k}, \pi_{2, k}, \cdots \cdots, \pi_{n, k}, \cdots \cdots, \pi_{N, k}\right) \\
= & \left(a_{1,1}, a_{1,2}, \cdots \cdots, a_{1, k}, a_{2,1}, a_{2,2}, \cdots\right. \\
& \left.\cdots, a_{N, 1}, a_{N, 2}, \cdots \cdots, a_{N, k}\right)
\end{aligned}
$$

と書き, LD送受信器アレイの離散出力として見なす.

LD送受信器アレイの出力を定量化するために,

$$
\Pi_{N, k}=\left(b_{1}, b_{2}, \cdots \cdots, b_{k \times N}\right)
$$

と1つの力学系による離散出力のように見なして，その 軌道の疑似的な軌道拡大率を計算する(ここでは疑似軌 道拡大率と呼ぶ)。まず, 遅延座標を用いて状態空間 ${ }^{11)}$ を再構成する。つまり，アトラクターの点は $\left(b_{i}, b_{i+1}\right)$ $(i=1,2, \cdots \cdots, k \times N-1)$ で与えられ, 状態空間内の $\left(b_{i}, b_{i+1}\right)$ の近傍の点 $\left(b_{i^{\prime}}, b_{i^{\prime}+1}\right)\left(i^{\prime}=1,2, \cdots \cdots, k \times N-1\right) を$ とる (本研究では 2 点の距離を 1.0 以下とした). 状態空間 上でこの近接2点 $\left(b_{i^{\prime}}, b_{i^{\prime}+1}\right)$ と $\left(b_{i^{\prime}}, b_{i^{\prime}+1}\right)$ の距離 $\varepsilon_{i, i^{\prime}}$ は $\sqrt{\left(b_{i+1}-b_{i^{\prime}+1}\right)^{2}+\left(b_{i}-b_{i^{\prime}}\right)^{2}}$ と書ける。このとき疑似軌道桩 大率は

$$
\lambda=\frac{1}{M} \sum_{\substack{i, i^{\prime}=1 \\ 0<\varepsilon_{i, i^{\prime}} \leq 1 \\ i<i^{\prime}}}^{k \times N-1} \ln \left|\frac{\varepsilon_{i+1, i^{\prime}+1}}{\varepsilon_{i, i^{\prime}}}\right|
$$

と表すことができる。ただし， $M$ は $0<\varepsilon_{i, i^{\prime}} \leq 1$ なる $\varepsilon_{i, i^{\prime}}$ の 個数である。これはSatoらによる離散出力からリアプノ フ指数を計算する手法 ${ }^{10)}$ を応用しているが, 全てのLD 送受信器アレイ出力を同じ状態空間上にプロットし疑似 的な軌道拡大率を計算するため, 異なるLD送受信器に よる点も疑似軌道拡大率に寄与する。受信者は, この方 法で疑似軌道拡大率を計算し, 予め定められたしきい值 によって「0」または「1」と決定する. 
なお，ここでは簡単のために2つのLD送受信器アレイ のみを考えているが, 送信器LDからの出力をモニター することで不正にバイナリーメッセージを読み取られる 可能性や，デイジットを反転させることでメッセージを 読み取られる可能性がある。しかし，この問題は，無数 の組み合わせのLD送受信器アレイと各々に対する疑似 軌道拡大率のしきい值を用意し，ディジットを決定する 度に用いるLD送受信器アレイを換えることで解決でき $b^{5)}$.

さて，本手法がハードウェア依存の秘匿通信手法であ ることを確認するために，パラメータ誤差に対するビッ トエラーレートを計算する。受信器LDのパラメータ $G_{r}$ と $\gamma_{r}$ が送信器LDのパラメータ $G_{t}$ と $\gamma_{t}$ に対して,

$$
\begin{aligned}
G_{r} & =G_{t}\left(1+\delta_{g}\right) \\
\gamma_{r} & =\gamma_{t}\left(1+\delta_{\gamma}\right)
\end{aligned}
$$

と書け, その他のパラメータは送受信器間で誤差を持た ないものとする。このパラメータ誤差 $\delta_{g}, \delta_{\gamma}$ に対する ビットエラーレートをFig. 2に示す. 疑似軌道拡大率の しきい值は1.42とした。これより, 特定のパラメー夕誤 差を持った受信器LDを持つ受信者のみが通信可能とな り, カオス同期には依存しないがハードウェア依存の秘 匿通信であることがわかる.

ハードウェア依存の秘匿通信を実際に行うには，通信 可能なハードウェアのパラメータを限定できることが必 要である.しかし， $\delta_{\gamma}=-\delta_{g}+0.2$ 直線を基準にみる と, ビットエラーレートの低い点が $\delta_{\gamma}<-\delta_{g}+0.2$ なる領 域にも広範囲に散らばり, ビットエラーレートの高い点 が $\delta_{\gamma}>-\delta_{g}+0.2$ なる領域にも点在する。 これは, LD送 受信器アレイを6対のLDで構成した場合 ${ }^{12)}$ と異なり, 通 信可能なハードウェアを十分に限定できていないことを 示し, 疑似軌道拡大率がパラメー夕誤差に対して変動し やすいことに起因している.

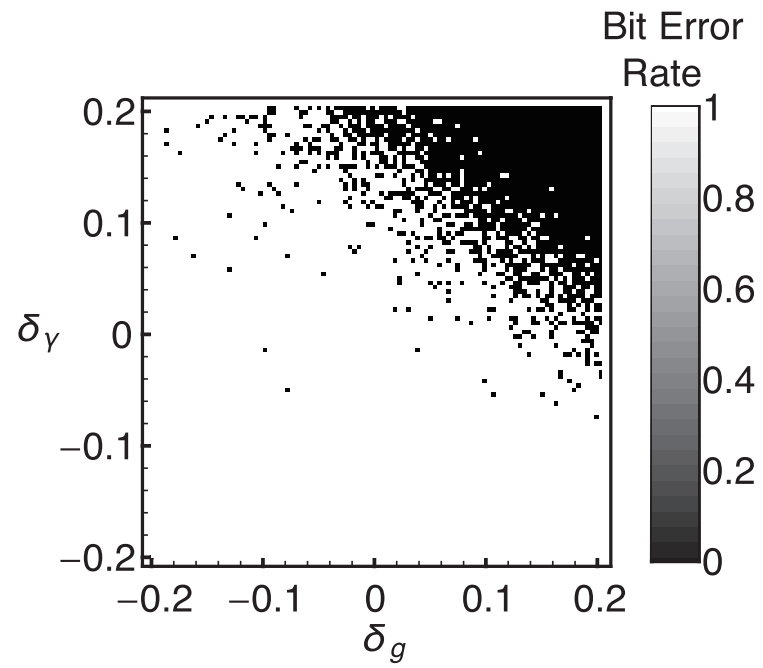

Fig. 2 Bit error rate of CLDTRAS discretely plotted against mismatch of carrier lifetime and differential gain in which the threshold of Lyapunov exponent is adjusted to 1.42 .

\section{3.ノイズを印加したLD送受信器アレイ}

続いて，送信器LDにノイズ信号を加えることで, Fig. 2のビットエラーレートが低い点と高い点の点在す る範囲を小さくすることを考える。「0」「1」のバイナリー ディジットに充てるLD送受信器アレイはいずれも4対の LDで構成される。「0」に相当するアレイ1の結合係数は $\eta=0.15, \quad 0.2, \quad 0.3,0.4$ であり，「1」に相当するアレイ2 の結合係数は $\eta=0.1 ， 0.2 ， 0.3 ， 0.4$ である. Fig. 2の場合 と異なり，アレイ2におけるLDt1のみ，しきい值電流の $1.0 \times 10^{-3}$ の大きさのノイズ信号を加えた駆動電流にて 発振させる。

このアレイを用いた場合にもパラメータ誤差 $\delta_{g}, \delta_{\gamma}$ に 対するビットエラーレートを計算する(Fig. 3)。疑似軌 道拡大率のしきい值は1.42とした。これより，特定のパ ラメータ誤差を持った受信器LDをもつ受信者のみが通 信可能となる。つまり，カオス同期には依存しないが ハードウェア依存の秘匿通信であることがわかる。ま た，Fig. 2とFig. 3を比較すると, Fig. 2ではビットエ ラーレートの低い点が $\delta_{\gamma}<-\delta_{g}+0.2$ なる領域にも広く散 らばっていたがFig. 3ではこの範囲は狭まり, $\delta_{\gamma}>-\delta_{g}+0.2$ なる領域ではビットエラーレートの高い点 を抑制することができる。これより，送信器LDの駆動 電流にノイズを加えることで，通信に用いるハードウェ アを限定できパラメータ誤差に対する耐性を高めること ができる。

この現象について状態空間上の $n=1$ のLD送受信器に 対応する点 $\mathrm{P}_{1, i}\left(a_{1, i}, a_{1, i+1}\right)(i=1,2, \cdots \cdots, k-1)$ を基準に考 える. 本研究で疑似軌道拡大率の計算に使わ机る点は, $\S 2 よ り こ の \mathrm{P}_{1, i}$ を中心として半径1.0の円内に含まれる点 のみとなる。今，駆動電流にノイズが印加された場合， $\mathrm{P}_{1, i}$ に摂動を加えると考えれば, 他のLD送受信器の出力 に対応する点が円の内側に含まれ易くなる。これによっ て, $n \neq 1$ なるLD送受信器の出力による疑似軌道拡大率

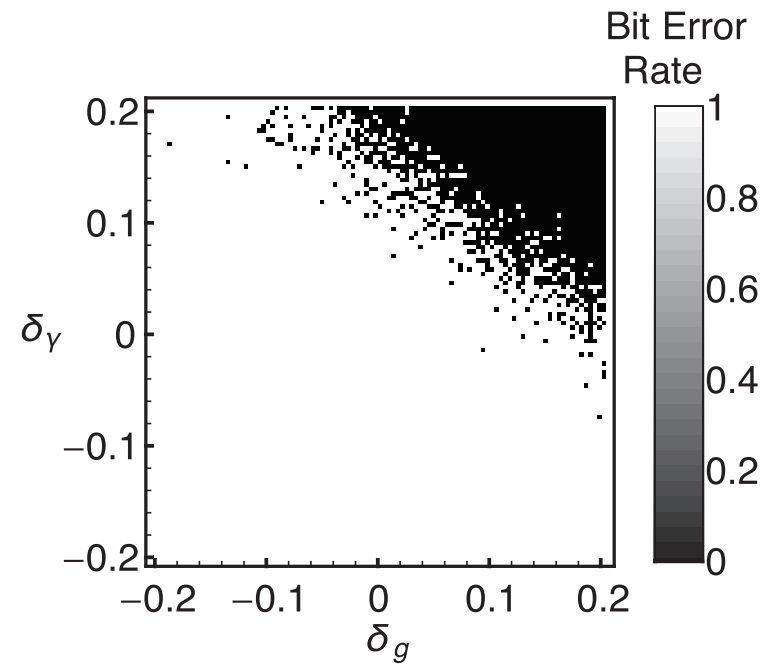

Fig. 3 Bit error rate of CLDTRAS with noisy drive current discretely plotted against mismatch of carrier lifetime and differential gain in which the threshold of Lyapunov exponent is adjusted to 1.42 . 
に与える効果が高まり, 疑似軌道拡大率はパラメー夕誤 差に対して変動し難くなる.

また, Fig. 3で駆動電流に印加するノイズの大きさを しきい值電流の $1.0 \times 10^{-3}$ としたことについてFig. 4の状 態空間を用いて考える。 $n \neq 1$ なるLD送受信器に対応す る点 $\mathrm{P}_{n, i}$, それを中心とする半径1.0の円 $\Sigma$, その円内に ある点 $\mathrm{P}_{1, j}$ を考える.この点 $\mathrm{P}_{1, j}$ がノイズによる摂動によ り円 $\Sigma$ の外に出てしまうことで疑似軌道拡大率が変動す る. 本研究では駆動電流としきい值電流の差がしきい值 電流の 0.02 倍であり, これはカオス振動の振幅 $\left(\sim 10^{2}\right)$ に対応しているので, 点 $\mathrm{P}_{1, j}$ を円 $\Sigma$ の半径 1.0 ほど振動さ せるには $2 \times 10^{-4}$ ぼのノイズを駆動電流に与える必要 がある.これよりも小さい振動を駆動電流に与えたとし ても点 $\mathrm{P}_{1, j}$ は円 $\Sigma$ の外に移ることはなく, 疑似軌道拡大率 に影響することは無い，そこで，本研究ではこの值より も十分に大きな $1.0 \times 10^{-3}$ 用いた.

次に, CLDTRASのチャンネルノイズに対する耐性を 調査する。 以下では, 各送信器LDと各受信器LDが $\delta_{g}=0.094, \delta_{\gamma}=0.094$ なるパラメータ誤差を持つ場合に ついて扱う。まず，Fig. 2に相当するLD送受信器アレイ を用いた通信について考える. Fig. 5の破線は, 送受信 器間に拈けるチャンネルノイズのSNR (signal-to-noise ratio)に対するビットエラーレートを示している。 ノイ ズを増やしていくと, チャンネルノイズの影響が支配的 になっていき $25 \mathrm{~dB}$ 付近で急激にビットエラーレートが 増加する。

また, Fig. 3に相当する送信器LD (LDtr1) の駆動電流 にノイズ信号を加えたLD送受信器アレイについて考え る。Fig. 5の実線は，送受信器間におけるチャンネルノ イズのSNRに対するビットエラーレートを示している. この場合も同様にビットエラーレートはSNRが $25 \mathrm{~dB}$ りも大きい範囲では小さく, SNRが減少していくと急激

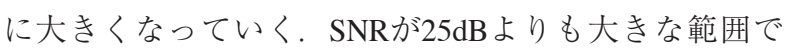
は, LDtr1の駆動電流にノイズ信号を加えないLD送受信 器アレイ程ではないがBER (Bit Error Rate)を抑えること

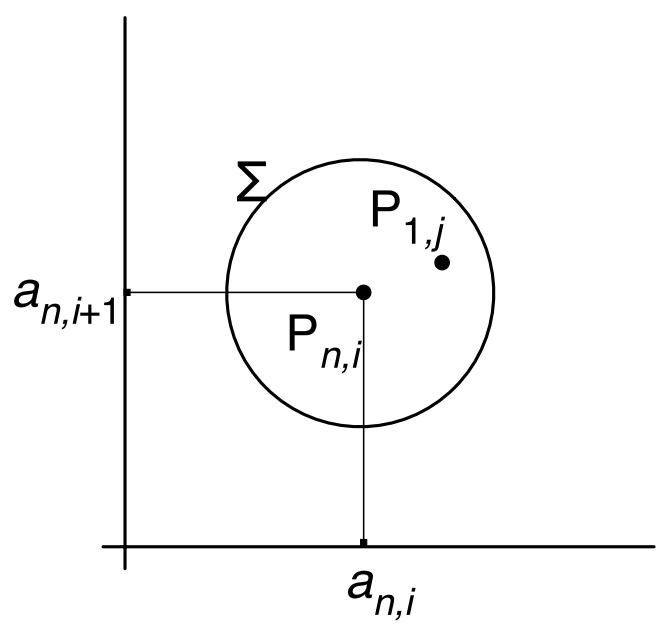

Fig. 4 Schematic of state space for the LD transmitter-receiver array. The point $\mathrm{P}_{n, i}$ belongs to $n$-th transmitter-receiver $(n \neq 1)$, and the point $\mathrm{P}_{1, j}$ belongs to 1 st transmitter-receiver.

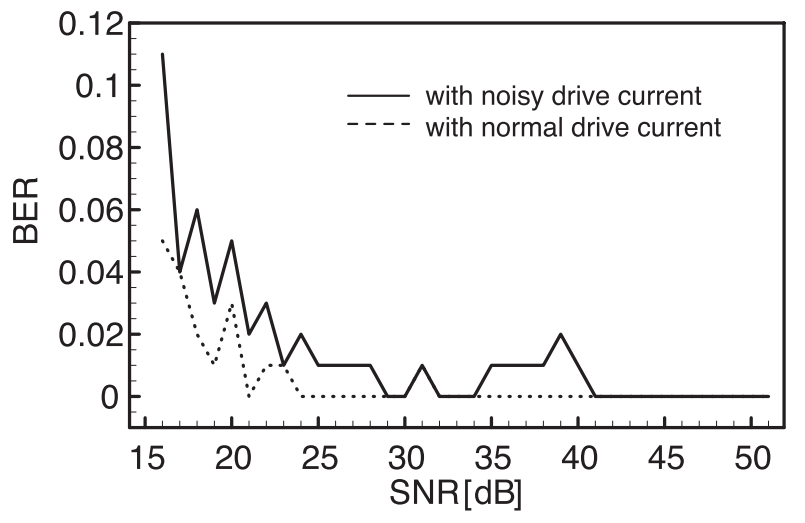

Fig. 5 Bit error rate (BER) plotted against signal-to-noise ratio $\left(\delta_{g}=0.094, \delta_{\gamma}=0.094\right)$. The solid line indicates BER with the array which contains the transmitter LD driven by noisy drive current, and the broken line indicates BER with the array which does not contain the transmitter LD driven by noisy drive current.

ができる，なお，本研究ではアレイ中のLD送受信器の 数は4個であるが, 送受信器対の数を増加させることで チャンネノイズに対する耐性をさらに強めることもでき る ${ }^{6)}$ が, 復号にかかる時間の増加とトレードオフとなる.

\section{4. まとめ}

LDの駆動電流にノイズを加えたLD送受信器アレイを 用いたCLDTRASによる光カオス通信について数值シ ミュレーションにより調査した。僅かなノイズを送信器 LDの駆動電流に印加することで, LD送受信器アレイを 構成するLD送受信器数が少ない場合でも, 通信に用い るハードウェアを限定できパラメー夕誤差に対する耐性 を高めることができることを示した。これにより CLDTRASにおいてメッセージの復号にかかる時間を増 やすことなく，ハードウェア依存の秘匿通信を達成でき る。しかし，チャンネルノイズに対する耐性が落ちると いう欠点もあり, さらなる改善が必要である.

\section{参考文献}

1) R. J. Jones, P. Rees, P. S. Spencer, and K. A. Shore: J. Opt. Soc. Am. B 18 (2001) 166.

2) U. Parlirz, L. O. Chua, L. Kocarev, K. S. Halle, and A. Shang: Int. J. Bifurcation Chaos 2 (1992) 5910.

3) J. Liu, H. Chen, and S. Tang: IEEE J. Quantum Electron. 38 (2002) 1184.

4) J. Otsubo: IEEE J. Quantum Electron. 38 (2002) 1141.

5) S. Ebisawa and S. Komatsu: Jpn. J. Appl. Phys. 43 (2004) 5910.

6) S. Ebisawa and S. Komatsu: Appl. Opt. 46 (2007) 4386.

7) R. Lang and K. Kobayashi: IEEE J. Quantum Electron. QE-16 (1980) 347.

8) G. H. M. van Tartwijk, A. M. Levine, and D. Lenstra: IEEE J. Sel. Top. Quantum Electron. 1 (1995) 466.

9) V. Ahlers, U. Parlitz, and W. Lauterborn: Phys. Rev. E 58 (1998) 7208.

10) S. Sato, M. Sano, and Y. Sawada: Prog. Theor. Phys. 77 (1987) 1.

11) R. C. Hilborn: Chaos and Nonlinear Dynamics (Oxford University Press, Oxford, 1994) Sections 4 and 9.

12) S. Ebisawa and S. Komatsu: Jpn. J. Appl. Phys. 46 (2007) 5512. 